\title{
Volker Reinhard, Luther der Ketzer. Rom und die Reformation
}

\section{Gérald Chaix}

\section{OpenEdition}

Journals

Édition électronique

URL : http://journals.openedition.org/ifha/9184

DOI : 10.4000/ifha.9184

ISSN : 2198-8943

\section{Éditeur}

IFRA - Institut franco-allemand (sciences historiques et sociales)

\section{Référence électronique}

Gérald Chaix, "Volker Reinhard, Luther der Ketzer. Rom und die Reformation », Revue de I'IFHA [En ligne], Date de recension, mis en ligne le 20 juin 2018, consulté le 24 septembre 2020. URL : http:// journals.openedition.org/ifha/9184; DOI : https://doi.org/10.4000/ifha.9184

Ce document a été généré automatiquement le 24 septembre 2020

(CIFHA 


\title{
Volker Reinhard, Luther der Ketzer. Rom und die Reformation
}

\author{
Gérald Chaix
}

\section{RÉFÉRENCE}

Volker Reinhard, Luther der Ketzer. Rom und die Reformation, München: C.H. Beck, 2016, 352 p., $24,95 €$ 
Spécialiste de la péninsule italienne à la Renaissance, Volker Reinhard veut répondre à une question simple : comment en est-on arrivé là? Pour ce faire, il a choisi de faire entendre les deux parties. Dans une première étape, qui court de 1483 à 1517, il présente les protagonistes et notamment la papauté de la Renaissance. Il note à propos du pape Léon X (1513-1521) que les comportements de ce dernier apparaissent aux hommes de la Curie tout à fait compatibles avec la fonction qu'il exerce, alors que pour les intellectuels $d u$ nord des Alpes, ils font de lui le modèle de l'épicurien. C'est l'occasion de faire le point sur la pratique du népotisme et de souligner sa signification dynastique et politique. V. Reinhard aborde aussi la question de la réforme de l'Église, dont la

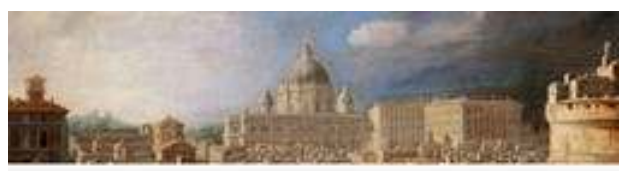

Volker Reinhardt LUTHER DER KETZER Rom und die Reformation

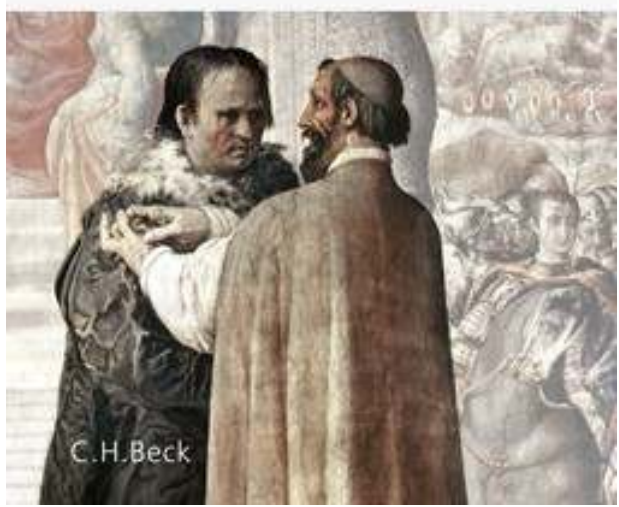
nécessité n'est niée par personne. Il souligne à cet égard la place particulière que l'Empire occupe au sein de la chrétienté. L'auteur étudie ensuite les critiques formulées par Luther dans les années 1517-1520. Elles portent d'abord sur la question des indulgences. Elles dérivent rapidement sur celle du pouvoir pontifical et celui des " autorités ». Le fossé qui se creuse rapidement n'est pas seulement théologique. Il est aussi socio-culturel et «national», opposant les Italiens raffinés aux barbares Allemands. En témoignent les affrontements successifs avec Prierias et Cajetan. La succession de l'empereur Maximilien et la volonté pontificale d'éviter à tout prix l'élection d'un Habsbourg accorde un sursis au règlement de l'affaire Luther car il faut ménager l'Électeur de Saxe.

L'élection de Charles Quint, le 28 juin 1519, relance la procédure. Le 15 juin 1520, la bulle Exsurge Domine laisse soixante jours à Luther pour se rétracter. Au même moment, Luther publie les écrits qui précisent sa vision : salut par la grâce, réduction du nombre des sacrements, affirmation du sacerdoce universel. Le pape est devenu l'Antéchrist. Le 10 décembre, la bulle est brûlée. C'est alors bien «Luther, le barbare » qui est condamné (1521-1523), comme en témoigne le regard que le nonce Aléandre jette sur la situation, notamment lors de la diète de Worms. Il est alors convaincu que Luther n'est qu'un sot et le paravent derrière lequel se cachent d'autres auteurs ! Pour la papauté, déjà préoccupée par la poussée ottomane et par l'état de l'Église, le danger allemand est un souci supplémentaire, même si l'attitude de l'empereur est rassurante. L'élection d'Adrien VI, qui n'arrive à Rome que le 28 août 1522, ne change guère la donne. La Curie est hostile à ce pape austère. Une hostilité que partagent même des réformistes comme Cajetan ou Campeggio. Luther dénonce de son côté "l'âne pontifical ». L'intermède d'Adrien VI (1522-1523) s'achève dès le 14 septembre 1523. Avec l'élection de Jules de Médicis, la lutte contre Luther reste à l'ordre du jour. Mais il faut simultanément mener les réformes nécessaires. La Curie romaine persiste à ne voir dans l'affaire luthérienne qu'un problème politique. Durant le pontificat de Clément VII (1523-1534), la personne 
même de Luther passe ainsi au second plan. Une nouvelle étape se dessine de 1534 à 1546 : celle de l'établissement durable de l'hérésie luthérienne. La Ligue de Smalkalde se forme en février 1531. Durant l'été 1532, la diète de Nuremberg aboutit à un compromis avec les "protestants ", dont l'empereur a besoin dans sa lutte contre les Turcs. Le duc Ulrich de Wurtemberg, acquis à la Réformation, recouvre le territoire qu'il avait perdu. Le cardinal Alexandre Farnese est élu pape sous le nom de Paul III (1534-1549) en octobre 1534. Un concile est convoqué dès janvier 1535. Il est sans doute trop tard. Une nouvelle "culture confessionnelle » est en train de se constituer en s'appuyant sur les écoles, les catéchismes, les cantiques, les images - que l'on songe à Cranach-, les prédications et les livres. L'« hérésie» luthérienne est en fait, selon V. Reinhard, un « choc culturel».

INDEX

Index chronologique : Période moderne

Thèmes : Histoire religieuse ; Histoire des mentalités

\section{AUTEURS}

\section{GÉRALD CHAIX}

Université de Tours, UMR 7323 